\title{
EDITORIAL
}

\section{The nutrition of microbes and man}

The human gastrointestinal tract is estimated to contain about $10^{14}$ micro-organisms, most of them in the colon. These outnumber the host's own body cells. Considering their vast potential metabolic activity, it is inconceivable that the microbial flora will not interact extensively with man's diet and affect body metabolism significantly. Yet relatively few micro-organisms have been studied in detail and we know very little about the 400-500 or so microbial species in the gut. We are particularly ignorant of how nutrition affects the balance between the species and the significance of minor or even major changes in diet. This is undoubtedly due mainly to the difficulties in studying the gut microflora. Heavy reliance has been placed on studies of the faecal flora, since they represent the only source of gut flora that is easily obtainable for experimentation but it has to be stressed that faecal material may not necessarily provide a true reflection of the balance of organisms in the gastrointestinal tract or their metabolism (Savage, 1977; Ducluzeau \& Raibaud, 1979). Gnotobiology (Gr. 'known life') techniques seek to standardize the gut flora by total elimination (germ-free state) or subsequent re-introduction of known species. There is some question about how far gnotobiotic animals provide a good model for understanding the role of the flora in vivo, since it is known that many anatomical and physiological changes occur in the gut of the germ-free animal (Coates, 1975; Ducluzeau \& Raibaud, 1979).

One of the most studied interactions between the gut microflora and the diet is the fermentation of carbohydrates that escape digestion in the upper part of the intestine. Examples may be non-starch polysaccharides (dietary fibre), lactose (in subjects with poor lactase activity) and sugar alcohols. The main end-products of such fermentations are the short-chain fatty acids (acetic, propionic and butyric acids) that are readily absorbed by the colonic epithelial cells and may provide a source of metabolic energy.

Two papers in this issue address the question of how to study gut microflora-nutrient interrelationships in the quite different ways referred to above, namely incubation of faeces and gnotobiology.

Vince et al. (1990) point out the difficulty of distinguishing purely physical effects of fibre transit through the bowel from the metabolic effects that follow breakdown of substrates by the intestinal bacteria. These authors used a faecal incubation system in vitro to examine the bacterial metabolic activity when diets contained 'normal' or 'twice-normal' quantities of carbohydrates not normally digested by the enzymes of the gut mucosa but metabolized by colonic bacteria. The readiness with which bacterial metabolism can change after relatively short periods of providing different carbohydrates (lactulose, pectin, arabinogalactan and cellulose) is of considerable interest. The increased butyrate :acetate ratio after prefeeding extra carbohydrate could also have significance for colonic metabolism and for the health of the colonic tissue. Any conclusions have to be tempered, however, by the uncertainty, discussed earlier, of whether faecal bacteria give a true reflection of bacterial metabolism in vivo. There is a further methodological problem in that short-chain fatty acids, which may accumulate in vitro but which would be constantly removed by absorption in vivo, may inhibit the growth and activities of at least some of the faecal bacteria.

There is currently great interest in the use of sugar alcohols in foods. They are sweet, yet 
they have low cariogenicity compared with dietary monosaccharides. Maltitol, for example, approaches sucrose in sweetness, has low cariogenicity, is slowly digested by small-intestinal enzymes and produces a blunted blood glucose response compared with sucrose. Because of its slow digestion, some maltitol reaches the colon and is a substrate for bacterial enzymes there.

Würsch et al. (1990) used the gnotobiology technique to distinguish between host and microflora contributions to the utilization of maltitol. The splitting of maltitol into monosaccharides was almost complete and it was the utilization of the monosaccharide alcohol, sorbitol, that limited the overall utilization of maltitol. Experiments with ${ }^{14} \mathrm{C}$ labelled maltitol in conventional compared with germ-free mice clearly demonstrated an important contribution of the microflora to the utilization of the sugar alcohol. An important difference between the physiology of the conventional and germ-free intestines was demonstrated by this work, namely that the specific activity of disaccharidases was increased up to $50 \%$ in the germ-free mice.

The experiments reviewed here are important in at least two respects. Firstly, for the many practical applications that will undoubtedly accrue from an understanding of the metabolism of dietary components by the gut microflora. Vince et al. (1990) mentioned the possible significance of changes in the acetate:butyrate ratio and the suppression of ammonia production associated with the microbial metabolism of carbohydrates which can benefit patients at risk from ammonia toxicity. A knowledge of the energy availability from food components hitherto regarded as having no energy value is also important. Secondly, for the fundamental insights such experiments may give into the biological significance of the human gut microfiora. Yet the approaches used are fraught with methodological difficulties and problems of interpretation that were hardly acknowledged by the authors. Until there are substantial improvements in the technology for studying nutrient-microflora interrelationships, we may not be able to expect significant advances in knowledge in this field.

M. I. GUR R

\section{REFERENCES}

Coates, M. E. (1975). The influence of the gut microflora on the nutrition of its host. Bibliotheca Nutritio et Dieta 22, $101-108$.

Ducluzeau, R. \& Raibaud, P. (1979). Ecologie Microbienne du Tube Digestif. Paris: Masson.

Savage, D. C. (1977). Microbial ecology of the gastrointestinal tract. Annual Review of Microbiology 31, $107-133$.

Vince, A. J., McNeil, N. I., Wager, J. D. \& Wrong, O. M. (1990). The effect of lactulose, pectin, arabinogalactan and cellulose on the production of organic acids and metabolism of ammonia by intestinal bacteria in a faecal incubation system. British Journal of Nutrition 63, 17.26.

Würsch, P., Koellreutter, B., Gétaz, F. \& Arnaud, M. J. (1990). Metabolism of maltitol by conventional rats and mice and germ-free mice, and comparative digestibility between maltitol and sorbitol in germ-free mice. British Journal of Nutrition 63, 7-15. 